\title{
Management of Ecological-Economic Processes of Pollution Accumulation and Assimilation in the Coastal Zone Marine Environment
}

\author{
I.E. Timchenko, I.K. Ivashchenko, E.M. Igumnova \\ Marine Hydrophysical Institute, Russian Academy of Sciences, Sevastopol, Russian Federation
}

\begin{abstract}
A model for managing the balance of pollution (getting into the sea with the coastal runoff) assimilation and accumulation, based on the negative feedback between the coastal economic system efficiency and penalties for the sea coastal zone pollution is proposed. The model is constructed by the Adaptive Balance of Causes method and is intended for finding a rational balance of profit from the use of assimilative resources of the marine environment and the costs of maintaining its quality. The increase of pollutions in the coastal zone is taken as proportional to the volume of product realization. The decrease of pollution concentration is related to the envi-ronment protection activities paid for by the production.

The model contains the agents for managing the volume of the economic system generalized production release. The agents control pollution accumulation rate at different ones of the biochemical processes resulting in the marine environment natural purification. Scenario analysis of ecological-economic processes in the "Land - Sea" system is carried out, and the dependencies of economic subsystem production profitability on penalty sanctions limiting the pollutant flux getting into the sea are constructed. Sea temperature and water mass dynamics effect on these processes is considered. The scenarios of their intra-annual variability are constructed. It is shown that the sea temperature and near-water wind consideration in the model have a significant effect on marine environment pollution level and production profitability.

The conclusion is that the proposed adaptive simulation model "Sea - Land" can be used for forecasting the scenarios of coastal subsystem production processes (the volume of generalized product manufacturing, production cost, profitability) in parallel with the forecast of pollution concentration in the sea scenarios.
\end{abstract}

Keywords: ecological-economic model, pollution accumulation and assimilation in the sea, consideration of sea temperature and sea surface wind.

DOI: $10.22449 / 1573-160 X-2017-1-68-83$

(C) 2017, I.E. Timchenko, I.K. Ivashchenko, E.M. Igumnova

(C) 2017, Physical Oceanography

Introduction. Sustainable development of the sea coastal zone suggests rational usage of marine resources. New intensively developing area of knowledge called "ecological economy" $[1,2]$ considers biodiversity of ecosystems and their stability in relation to polluting substances (which get into the marine environment due to economic activity taking place at the shore and in the shelf zone of the sea) as the main marine resources. Assimilative capacity of marine ecosystems is gaining importance with intensification of production and population density increase in the coastal territories. Therefore, a control over a level of marine environment pollution with industrial, agricultural and domestic wastes [3] becomes more and more urgent.

This paper is based on the concept of controlled balance of accumulation and assimilation of pollutions getting into the sea with coastal runoff in the form of substances that upset natural chemical-biological equilibrium of the coastal marine ecosystem. The main pollution sources are industrial and domestic wastes in the 
form of suspended and dissolved organic matter, toxic metals, phosphorus compounds and other chemical compounds. They have significant impact on coastal ecosystem when the velocity of pollutant flow (getting into the sea) exceeds the rate of their assimilation with the marine environment. Pollution accumulation and assimilation balance management should be based on this principle.

The purpose of this paper was to link economic benefit, obtained by manufacture from the use of the sea and waste utilization, with the costs necessary for maintaining a normal marine environment ecological condition. To achieve the desired objective, a conceptual model of ecological-economic system unifying the processes that accompany the release of product with the processes of pollution accumulation and assimilation was developed.

The concept of marine environment assimilative capacity in relation to the chemical-biological processes, taking place in marine ecosystems, is a particular case of more common concept of environmental resource capacity that limits the development of processes in complex systems which depend on finite volume of development resources. Economic product and services production systems situated in a coastal zone have limited possibilities of production release due to finite material, financial and other resources, and marine ecosystems have a finite assimilative capacity. Therefore, for the construction of ecological-economic models of the sea coastal zone it is convenient to use general adaptive method of balance (ABC-method) based on complex system adaptation to the environmental conditions with regard to existing resource limitations [4].

In the paper [5] a model (constructed using ABC-method) for managing the process scenarios in ecological-economic "Sea - Land" system is proposed. It is intended for finding rational balance of incomes (obtained from marine resource use) and expenditures for maintaining marine environment quality by means of scenario analysis of impact of economic sanctions for pollution on marine ecosystem processes. The increase of pollution concentration in marine environment was taken as proportional to the volumes of product realization, and the concentration decrease is related to environment protection measures sponsored by production.

In the present study we used a somewhat different scheme of marine environment pollution level management. A general model (constructed according to the criterion of balance of pollution accumulation and assimilation rates in the sea coastal zone) of production management of some generalized product of coastal social-economic system is considered.

A method for model construction. Let us consider the essence of ABCmethod for model construction briefly $[4,6]$. We suppose that for the description of processes in ecological-economic system a multitude of interrelated processes $0 \leq u_{i} \leq 2 C_{i}$ characterizing the motion to the desired modeling objective should be used $u_{i}$ variables have intra-system effect on each other according to cause-effect relationships which are assumed to be known. In the simplest case these relations are linear correlations:

$$
u_{i}=\sum_{j=1, i \neq j}^{n-1} a_{i j} u_{j}+C_{i},
$$

where $a_{i j}$ are the coefficients of intra-system effects, $n$ is a number of variables, $C_{i}$ is their average values. 
Two main assumptions are introduced in ABC-method. The first assumption is the following: there is a stationary state of system (1) equilibrium in which it stay in the absence of any external effects $\left(A_{i}=0\right)$. In this state the values of variables may be considered as deviations from their mean values caused by intra-system effects. Therefore, stationary condition is determined by the specified set of $C_{i}$ mean values and $a_{i j}$ effect coefficients.

The second assumption is the following: the balance of intra-system and external effects is kept within the system. It is related to the resistance of natural and economic systems against external effects $A_{i}$. It is assumed that all types of ecosystems have this property, as the organisms living in them strive to adapt for varying environmental conditions in order to survive. Therefore, varying external effects on ecosystem result in the set of dynamic balance of conditions: the values of ecosystem variables constantly "monitor" external effects and adapt to them within their variability ranges. The same property extends to economic systems, if the preservation of cause-effect relations (the system structures) at external effects (managements) is insured. Thus, the property of adaptation to external effects mean the preservation of balance of intra-system and external effects:

$$
u_{i}=\sum_{j=1, i \neq j}^{n-1} a_{i j} u_{j}+C_{i}+A_{i} .
$$

Owing to these assumptions, in the ABC-method of modeling a universal (module) equation, the solution of which is the expression (2), is used. The application of this equation significantly simplifies the problem of construction of $\mathrm{ABC}$-model system of equations which acquires a standard form:

$$
\frac{d u_{i}}{d t}=2 r_{i} u_{i}\left[C_{i}-\left(u_{i}-\sum_{j=1, j \neq i}^{n-1} a_{i j} u_{j}-A_{i}\right)\right] .
$$

It is obvious that balance relations (2) are the solutions of the system of equations (3). In the series of studies $[4,6]$ it is shown that these solutions are stable and unique in the domain of variable value variation of the model $0<u_{i} \leq 2 C_{i}$ upon the condition that intra-system and external effects do not remove the variables out of this domain:

$$
u_{i}=I F\left[u_{i}<0 ; 0 ; \operatorname{IF}\left(u_{i}>2 C_{i} ; 2 C_{i} ; u_{i}\right)\right] .
$$

Moreover, numerical solution of system of equations (3) has a rapid convergence of iteration processes even when using the simplest Euler scheme. This is due to the fact that in each of equations (3) variable value variation rates are related to the second-order varying negative feedbacks themselves which stabilize the solutions equations. As ABC-models of the form (3) systems provide mutual adaptation of model variable values to each other and to external effects, they form a class of adaptive models $[4,6]$.

High stability of ABC-model system of equation solution provides a wide use of non-linear logic operators - management agents in them. Application of management agents make it possible to change the scenarios of modeling 
processes, bringing them closer to the expected objectives of sustainable development. Resource limitation agents of ecological-economic development processes are an important special case. They are applied in those cases when system product formation occurs with the simultaneous use of several types of resources. In each moment of time the reserves of one of the resources are minimal in relation to other types of resources. This minimal resource type will limit the system product increase and system (3) ABC-model equations will take the following form:

$$
\begin{gathered}
\frac{d u_{i}}{d t}=2 r_{i} u_{i}\left\{C_{i}-\left[u_{i}-\sum_{j=1, j \neq i}^{k-1} a_{i j} u_{j}-A G_{i} \arg \min \left(a_{i k} u_{k}, \ldots, a_{i n} u_{n}\right)-A_{i}\right]\right\}, \\
A G_{i} \arg \min =I F\left(a_{i l} u_{l}=M_{l} ; a_{i l} u_{l} ; 0\right), M=\min \left(a_{i k} u_{k}, \ldots a_{i l} u_{l}, \ldots, a_{i n} u_{n}\right) .
\end{gathered}
$$

Coefficients of effects $a_{i j}$, in accordance with balance relation (2), characterize the increment in the quantities of each product $u_{i}$ through the use of resources for its formation $u_{j}$. In general case, if $u_{i}=u_{i}\left(u_{j}\right)=a_{i j} u_{j}$, then

$$
a_{i j}=\frac{\partial u_{i}}{\partial u_{j}} .
$$

The assessments of the coefficients of effects can be obtained by the regression analysis of observation time series for each pair of $u_{i}$ and $u_{j}$ processes. It was pointed out in $[4,6]$ that effect coefficients $a_{i j}$ are related to each other by mutual correlative relations $R_{i j}=E\left\{u_{i} u_{j}\right\}$ and $G_{i j}=E\left\{u_{i} A_{j}\right\}$. Therefore, they form ABC-model of adaptive system themselves. In this model they exercise the functions of variables interconnected with correlative relations. Coefficients of effects should be determined at $(-0,5 ; 0,5)$ intervals, whereas the variables of ABCmodel are determined at the intervals of positive values $0 \leq u_{i} \leq 2 C_{i}$. So, this is necessary to introduce the following ABC-model system of equations for $a^{\prime}{ }_{i j}$ variables which differ from the effect coefficients by a constant value $0.5\left(a_{i j}^{\prime}=a_{i j}+0,5\right)$ :

$$
\begin{gathered}
\frac{d a_{i j}^{\prime}}{d t}=a_{i j}^{\prime}\left[1-2\left(a_{i j}^{\prime}-R_{i j}+\sum_{p=1, p \neq i}^{n-2} a_{i j}^{\prime} R_{p j}+G_{i j}\right)\right],(i, j=1,2, \ldots, n),(i \neq j), \\
a_{i j}^{\prime}=\operatorname{IF}\left[a_{i j}^{\prime}<0 ; 0 ; \operatorname{IF}\left(a_{i j}^{\prime}>1 ; 1 ; a_{i j}^{\prime}\right)\right],
\end{gathered}
$$

Thus, the systems of equations (3) and (7) under additional conditions (4) and (8) allow one to construct an adaptive model of the ecological and economic system of the sea coastal zone on the basis of a scheme of cause-effect dependencies between its components.

An adaptive model for managing the level of coastal marine environment pollution from controlled coastal runoff. Additional assumptions are taken to construct the model corresponding to objective of this work which was formulated PHYSICAL OCEANOGRAPHY NO. 1 (2017) 
above. It was considered that the level of the sea pollution by the coastal runoff is proportional to the volume of the generalized product produced by the coastal territory economic system. Averaged over the volume of coastal marine water area integral assessment

$$
P L=\sum_{k=1}^{m} \rho_{k} P L_{k}+P L_{0},
$$

which was a sum of $m$ types of $P L_{k}$ pollutant concentrations (which are the most harmful for the ecosystem biodiversity and exceed in value the assessment of average multi-year (background) concentration of $P L_{0}$ pollutants) weighted with $\rho_{k}$ weights, was applied as a pollution level characteristic. Therefore, the system for pollution level management should not exceed the maximum permissible values (MPV) of $P L_{k}^{*}$. It was assumed that $P L$ value may be managed by remote or contact observations, and MPV integral value of $P L^{*}$ is also known.

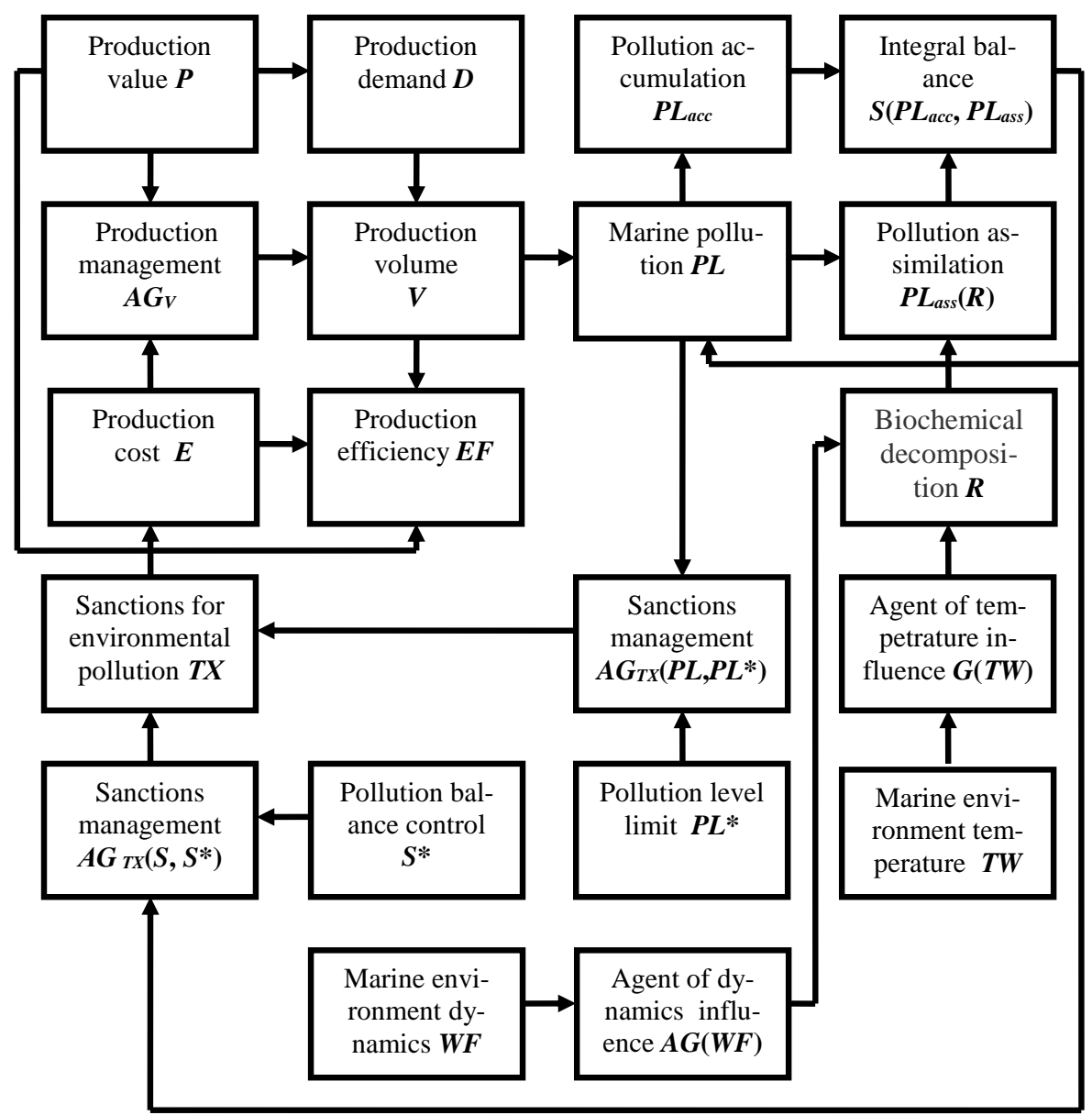

Fig. 1. Conceptual model for managing the ecologic-economic processes of pollution accumulation and assimilation in the coastal marine environment 
With the introduced assumptions, conceptual model for managing the economic-ecological system is based on dependence of coastal economic system products and services production profitability on sanctions imposed on it for deterioration of marine environment ecologic condition in the coastal water area. Current values of pollutant concentration $P L(t)$ (getting into the sea with the coastal runoff) and integral balance of volumes of accumulated and assimilated pollutants $S(t)$ are applied to assess this condition. $P L^{*} \mathrm{MPV}$ and permissible value of integral balance $S^{*}$ were taken as management criteria. Conceptual model for managing the system with the mentioned model variables and management agents is represented in Fig. 1.

In the management system the operations were carried out in the following sequence. With the increase in demand for the generalized product $D$, the production volume $V$ and the volume of pollutants getting into the sea (on which the concentration of pollutants in the marine environment $P L$ depended) also increased. Management agent $A G_{T X}\left(P L, P L^{*}\right)$ monitored the increase in pollution concentration and set the values of $T X$ sanctions, greatening the production costs $E$. Management agent $A G_{V}(P, E)$ compared production costs $E$ with the market value of product $\mathrm{P}$ and reduced (or stopped) production release when the $E F$ profitability condition was violated: production cost became higher than $(E>P)$ cost. If the pollution level exceeded $P L^{*}$ value, and additional penalty for exceeding the pollution MPV was imposed. With a reduction of production volume a reverse sequence of events took place: the volume of pollutants getting into the sea and the amount of sanctions decreased, and, consequently, the production cost also decreased. When the condition $E<P$ came, $A G_{V}(P, E)$ management agent restored the production release up to the existing level of demand for it.

Integral balance of pollutant accumulation and assimilation was considered as $S(t)$ difference of two components:

$$
\begin{gathered}
S(t)=S_{a c c}(t)-S_{a s s}(t), \\
S_{a c c}(t)=a_{P L / V} \int_{0}^{t} V(\tau) d \tau, \\
S_{a s s}(t)=a_{P L / V} \int_{0}^{t} R(\tau) V(\tau) d \tau,
\end{gathered}
$$

where $S_{a c c}(t)$ is an accumulated amount of pollutions; $S_{a s s}(t)$ is their accumulated assimilated amount. $R(t)$ function - relative pollution assimilation rate (assimilation coefficient) - was a relation of $S_{\text {ass }}^{\prime}(t)$ pollution assimilation rate to the rate of their accumulation $S_{a c c}^{\prime}(t)$. Under the natural condition $S_{a s s}^{\prime}(t) \leq S_{a c c}^{\prime}(t)$, the values of $R(t)$ function are enclosed in $(0 \leq R(t) \leq 1)$ interval. The function depended on biochemical pollutant decomposition reactions, the sea temperature $T W$ and also on transport and turbulent diffusion of water masses. 
The ratio of pollutant accumulation and assimilation rates in the sea determined their concentration. As the marine environment assimilative capacity is always limited, there was an upper boundary of assimilation rate at which assimilation coefficient had the maximum value $R_{\max } \leq 1$. The balance of pollutions (10) took $S^{*}$ value at that. Above this boundary, with $S(t)>S^{*}$, the rate of pollutant refining into the products harmless to the marine ecosystem began significantly falling behind the rate of their accumulation. A rapid increase in the pollutant concentration took place. It threatened to ecosystem degradation, as $R(t)$ assimilation coefficient became an exponentially decreasing function:

$$
R(t)=I F\left[S<S^{*} ; R_{\max } ; R_{\max } \exp \left(-\alpha_{R} \tau\right)\right] .
$$

In order to construct a model of pollution accumulation and assimilation within the framework of the integral approach adopted in this paper, the following assumptions are introduced:

- $R(t)$ function depends on the intensity of biochemical pollution decomposition reactions, on $T W$ sea temperature, transport and turbulent diffusion of water masses and determines the intensity of pollution accumulated volume decrease per unit time $(0 \leq R(t) \leq 1)$;

- a modulus of near-water wind $W F$ characterizes the impact of water mass dynamics on assimilation rate;

- with the rise of temperature and near-water wind velocity increase, the assimilation rate of accumulated pollutions rises according to exponential law with saturation.

These assumptions allowed one to represent $R(t)$ function by means of $A G[T W(t)]$ and $A G[W F(t)]$ management agents:

$$
\begin{gathered}
R(t)=I F\left\{R(t)>1 ; 1 ; \operatorname{IF}\left[S<S^{*} ; 1 ; R(t) \exp \left(-b_{R} \tau\right)\right]+A G[T W(t)]+A G[W F(t)]\right\},(14) \\
A G[T W(t)]=a_{R / T W} I F\left\{T W(t)>0 ; 1-\exp \left[-b_{R / T W} T W(t)\right] ; 0\right\} \\
A G[W F(t)]=a_{R / W F} I F\left\{W F(t)>0 ; 1-\exp \left[-b_{R / W F} W F(t)\right] ; 0\right\}
\end{gathered}
$$

Thus, the balance of volumes of accumulated and assimilated pollutants $S(t)$ depended on $R(t)$ value. With $R(t)$ coefficient equal to one, $100 \%$ of all incoming pollutions were assimilated, the pollutions were not accumulated and their concentration in the sea was determined by the current production volume only. In this case $(R(t)=1)$ balance of volumes of accumulated and assimilated pollutions (10) had $\left(0, S^{*}\right)$ interval of values at which the marine ecosystem was able to adapt to such pollution levels. At $S>S^{*}, R(t)$ coefficient became less than one and accumulated pollution level exceeded the maximum permissible value. That caused a dangerous ecological state for the ecosystem.

In order to take into account these assumptions in the scheme of ecologicaleconomic system management (Fig. 1), in parallel with the above described chain of negative feedback between production volume $V(t)$ and $P L(t)$ marine environment pollution level, one more management chain (which controlled the 
dynamics of volume of accumulated and assimilated pollutions) was applied. $A G_{T X}\left(S, S^{*}\right)$ agent, which increased $T X$ sanctions for pollution when the balance of volumes of accumulated and assimilated pollutions $S(t)$ exceeded the value $S^{*}$, determined by the adaptive properties of marine ecosystem, was included in this additional control loop:

$$
A G_{T X / S^{*}}\left(S, S^{*}\right)=I F\left\{S<S^{*} ; 0 ; a_{T X / S-S^{*}}\left(S-S^{*}\right)\left[1-\exp \left(-b_{T X / S-S^{*}} \tau\right)\right]\right\} .
$$

Dynamical equations of the model of ecological-economic system. The equations were constructed by means of ABC-method modular formulas (5), (6) and the scheme of effects of modeling processes depicted in Fig. 1. They are represented by the system of equations (16) - (22). The equation for demand for the system production includes $D^{*}$ external effect function (which determined the dynamics of demand) and $C_{D}$ constant - the average value of demand:

$$
\begin{aligned}
& \frac{d D}{d t}=2 r_{D} D\left[C_{D}-\left(D_{i}+a_{D / P} P-D^{*}\right)\right], \\
& D=I F\left[D<0 ; 0 ; I F\left(D>2 C_{D} ; 2 C_{D} ; D\right)\right] .
\end{aligned}
$$

$A G_{V}(P, E)$ management agent, which reduced or stopped the production depending on the value of $V^{*}$ management constant, was included in the equation for products and services production volume:

$$
\begin{gathered}
\frac{d V}{d t}=2 r_{V} V\left\{C_{V}-\left[V+A G_{V}(P, E)-a_{V / D} D\right]\right\} . \\
V=I F\left[V<0 ; 0 ; I F\left(V>2 C_{V} ; 2 C_{V} ; V\right)\right], \\
A G_{V}(P, E)=I F\left\{P>E ; 0 ; V^{*}\left[1-\exp \left(-b_{V} \tau\right)\right]\right\} .
\end{gathered}
$$

Taking into account (10) - (12) relations, a logical operator considering the value of accumulating pollution assimilation function $R(t)$ was included in the equation for the pollution concentration:

$$
\begin{gathered}
\frac{d P L}{d t}=2 r_{P L} P L\left\{C_{P L}-\left[P L-a_{P L / V} I F\left\{R(t)=1 ; V(t) ; \int_{0}^{t}[1-R(\tau)] V(\tau) d \tau\right\}\right]\right\}, \\
P L=I F\left[P L<0 ; 0 ; I F\left(P L>2 C_{P L} ; 2 C_{P L} ; P L\right)\right] .
\end{gathered}
$$

$a_{T X / P L} P L$ summand in the equation for the sanctions set a penalty for the current flow of pollution. $A G_{T X / P L^{*}}\left(P L, P L^{*}\right)$ management agent increased the amount of this penalty when pollution level exceeded $P L^{*}$ MPV, and $A G_{T X / S^{*}}\left(S, S^{*}\right)$ agent added one more component (15) to the sanctions when the integral balance of volumes of accumulated and assimilated pollutions $S$ became more than $S^{*}$ :

$$
\begin{gathered}
\frac{d T X}{d t}=2 r_{T X} T X\left\{C_{T X}-\left[T X-a_{T X / P L} P L-A G_{T X / P L^{*}}\left(P L, P L^{*}\right)-A G_{T X / S^{*}}\left(S, S^{*}\right)+T X^{*}\right]\right\}, \\
T X=I F\left[T X<0 ; 0 ; I F\left(T X>2 C_{T X} ; 2 C_{T X} ; T X\right)\right]
\end{gathered}
$$




$$
A G_{T X / P L^{*}}\left(P L, P L^{*}\right)=I F\left\{P L<P L^{*} ; 0 ; a_{T X / P L^{*}}\left(P L-P L^{*}\right)\left[1-\exp \left(-b_{T X / P L^{*}} \tau\right)\right]\right\},
$$

where $T X^{*}$ is a constant regulating the amount of sanctions.

$E^{*}$ constant, which considered all the manufacturing expenses relating to the release of a unit of production, was included in the equation for production costs:

$$
\begin{gathered}
\frac{d E}{d t}=2 r_{E} E\left[C_{E}-\left(E-a_{E / T X} T X+E^{*}\right)\right], \\
E=I F\left[E<0 ; 0 ; I F\left(E>2 C_{E} ; 2 C_{E} ; E\right)\right] .
\end{gathered}
$$

To assess $E F$ production economic profitability, a logarithm of relation of economic system profits accumulated over the time period $(0, t), I_{a c c}(t)$ to expenses $E_{a c c}$ accumulated over the same time period is applied:

$$
I_{a c c}=\int_{0}^{t} P^{*} V(t) d t, \quad E_{a c c}=\int_{0}^{t} E(t) V(t) d t, \quad E F=\ln \frac{1+I_{a c c}}{1+E_{a c c}} .
$$

Computational experiments with the model. A series of computational experiments were carried out with the constructed model. For the convenience of comparing the process scenarios, $u_{i}^{\prime}$ dimensional variables of model and external effects $A_{i}^{\prime}$, which have $C_{u_{i}^{\prime}}$ and $\bar{A}_{i}^{\prime}$ average values, respectively, were represented in dimensionless form $u_{i}$ and were reduced to the general variability interval $(0$, $10)$ by means of the following identities:

$$
5 u_{i}^{\prime}=C_{u_{i}^{\prime}} u_{i}, \bar{A}_{i} A_{i}^{\prime}=\bar{A}_{i}^{\prime} A_{i} .
$$

In the first experiment controllability of the model and its sensitivity to the variation of parameters determining the impact of sanctions on pollution level and production profitability were studied. The values of model parameters are represented below:

$\begin{array}{cccccccc}a_{D / P} & 0,3 & b_{V} & 0,1 & C_{u i} & 5,0 & D^{*} & 2,0 \\ a_{V / D} & 1,0 & a_{R / W F} & 1,0 & r_{i} & 1,0 & V^{*} & 5,0 \\ a_{E / T X} & 0,8 & b_{R / T W} & 0,1 & a_{T X / S, S^{*}} & 0,5 & E^{*} & 3,0 \\ a_{T X / P L} & 0,4 & b_{R / W F} & 0,5 & b_{T X / S, S^{*}} & 0,2 & S^{*} & 5,0 \\ a_{P L / V} & 1,0 & b_{T X / P L^{*}} & 0,1 & a_{R / T W} & 1,0 & P L_{0} & 2,0 \\ a_{T X / P L^{*}} & 0,5 & a_{T X / P L^{*}} & 0,7 & P^{*} & 4,5 & P L^{*} & 3,5\end{array}$

In the first series of experiments thermodynamic factors $T W(t)$ and $W F(t)$ were not taken into account in order to assess subsequently their effect on pollution accumulation and assimilation balance. The results of computations are represented in Fig. 2.

At first, the scenarios of $R(t)$ and $S(t)$ functions were constructed by the formulas (13), (14) of pollution accumulation and assimilation model (Fig. 2, $a$ ). The maximum value of $R_{\max }$ assimilation coefficient is equal to 1.0. Specified assimilative environment capacity $\left(S_{a s s}^{*}=5\right.$ ) provided the equality of pollution 
accumulation and recovery rates to the $125^{\text {th }}$ step of computations, when assimilation rate reduced and $S_{a s s}$ scenario became falling behind the $S_{a c c}$ scenario. From this time point integral balance $S$ began to increase sharply.

An unfavorable case for ecosystem, when pollution assimilation rate is low ( $R_{\max }=0.05$ ) but the penalties for air pollution are absent $(T X=0)$, is considered next. These scenarios are given in Fig. $2 b-d$. As follows from Fig. 2, $b$, product costs $E$ was significantly lower than $P^{*}$ product cost. Therefore, product release occurred at the level of demand for it $(V=D=5,6)$, and production profitability $E F$ was constant and high (Fig. 2,d). Due to low assimilation rate, pollution assimilation and accumulation balance reached $S^{*}$ value at the $6^{\text {th }}$ step of computations when a dramatic reduction of $R_{\max }$ coefficient value took place (Fig. 2, d). After that, the pollution level increased in proportion to the pollutant accumulation in the marine environment (Fig. 2,c).
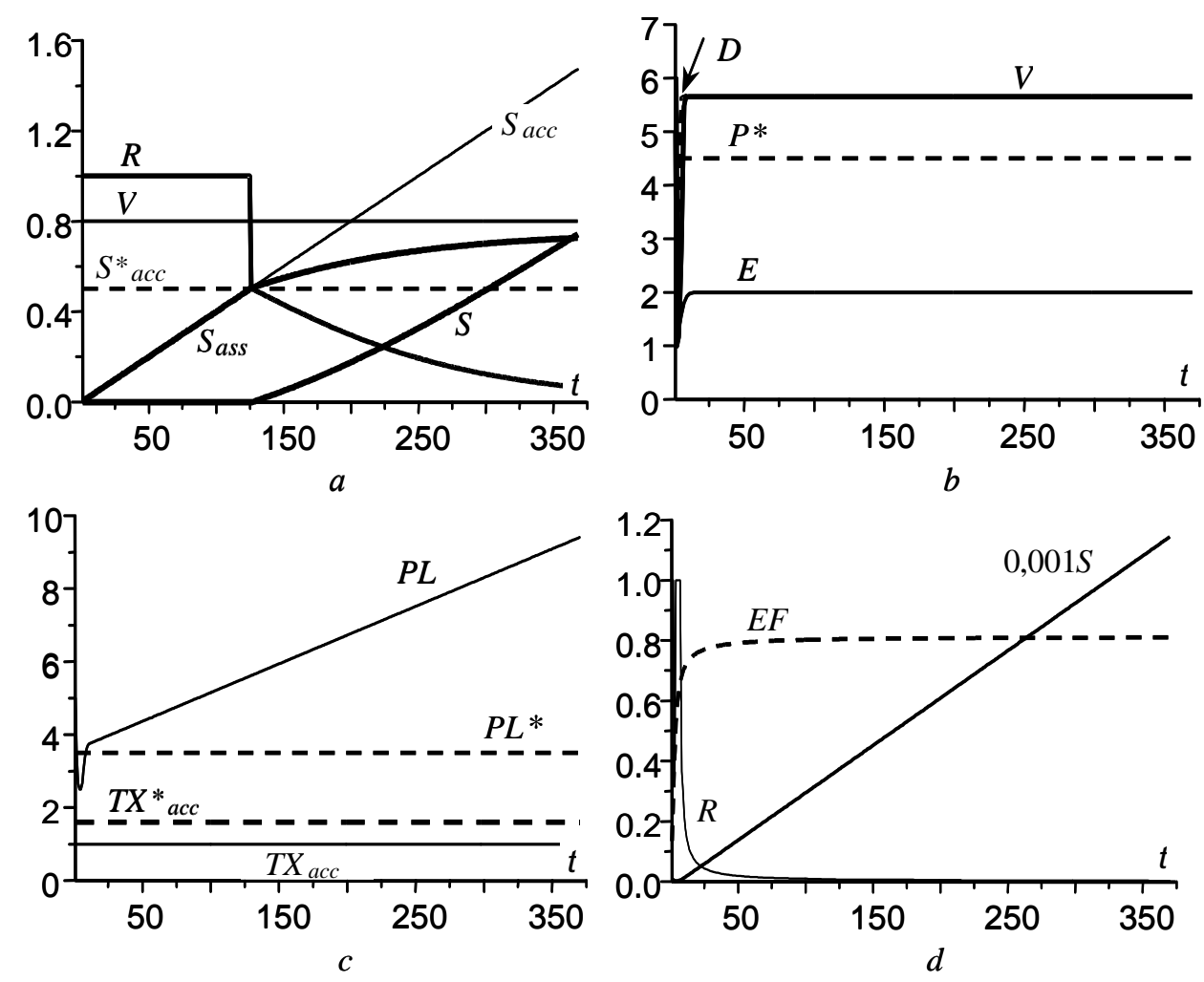

Fig. 2. The results of experiments with a constant volume of production without imposing economic sanctions and with no regard to the temperature and dynamic processes in the sea: $a$ - model example of $S$ balances of pollution accumulation $S_{a c c}$ and assimilation $S_{a s s}$ at $R_{\max }=1.0$ and $S^{*}{ }_{a c c}=0.5 ; b-d$ scenarios of ecological-economic processes at $R_{\max }=0.05$

Then, the sanctions for pollution were imposed and experiments with different rates of accumulated pollution assimilation, specified by the selection of $R_{\max }$ 
function volume, were performed. Background value of $P L_{0}$ concentrations in the experiments was taken as equal to 2 , and assimilative capacity $S^{*}$ was characterized by the value equal to 3.5 . Computation results obtained at different rate of accumulated pollutant assimilations are represented in Fig. 3.

At different assimilation rates the scenarios of processes in the ecologicaleconomic management system substantially differed in their types (Fig. 3), although the management scheme was the same. In experiments the results of which are given in Fig. 3, the penalties with assimilation rates within $R_{\max }(1.0$, $0.05)$ range of values provided a pollution level below the maximum permissible value $\left(P L<P L^{*}\right)$. Therefore, the scenario management was performed by means of $A G_{T X / S^{*}}\left(S, S^{*}\right)$ and $A G_{V}(P, E)$ agents according to general scheme.

As an example, we are to consider the operations of system management at pollutant assimilation rate equal to $100 \%$ of their accumulated volume per time unit, i.e. when $R_{\max }=1.0$ (Fig. 3,a,c). In the initial time period (up to $160^{\text {th }}$ step of computations) product release $V$ coincided by its value with a demand for it $D$, and pollution level $P L=2.0$ remained constant due to equality of pollution accumulation and assimilation rates. However, $T X$ penalties increased within this period as the accumulated volume of pollutants exceeded the prescribed threshold value $S^{*}=3.5$.
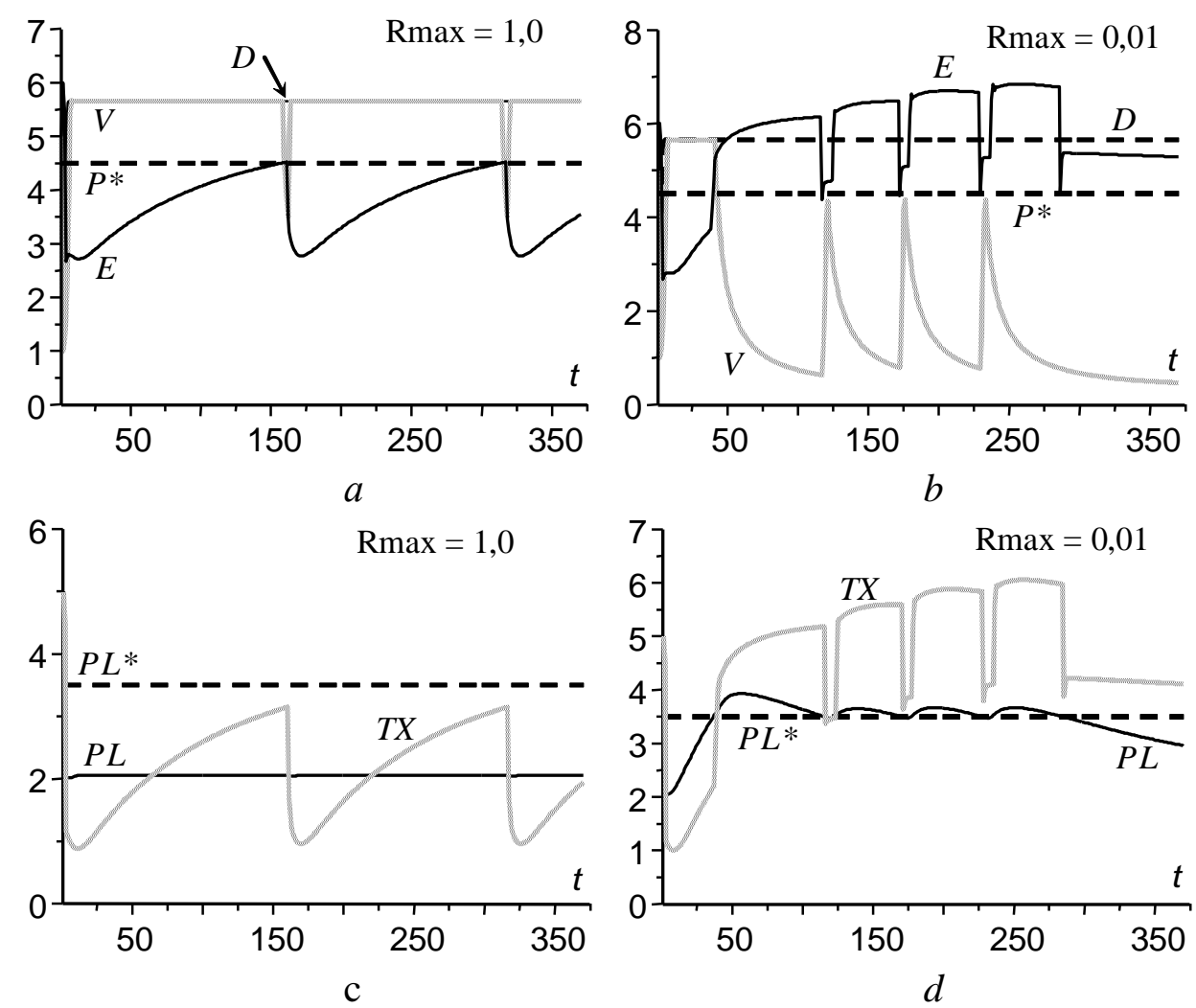

Fig. 3. Scenarios of processes in the ecological-economic management system at different pollutant assimilation rates. 
With the increase of penalties, production cost $E$ also rose and exceeded the cost of manufactured products at the $160^{\text {th }}$ step. With increasing penalties, the cost of production of $\mathrm{E}$ increased and at the 160th step it exceeded the cost of manufactured products. The production has ceased to be profitable, and management agent sharply reduced product release $V$. Decline in production was short-termed: as pollutant accumulation rate and production cost decreased, the production became profitable again and product release increased up to the level of demand. Further, the considered cycle of management operations repeated.

In Fig. 3, $b, d$ an example of low assimilation rate, equal to $1 \%$ of pollutant volume per unit time, is represented. In this case, with the same product release initial volume (dashed line $V$ in Fig. 3, b) PL concentration already exceeded MPV $\left(P L^{*}=3.5\right)$ at $39^{\text {th }}$ time step. Scenarios of processes became more unsustainable, as in addition to $A G_{T X / S^{*}}\left(S, S^{*}\right)$ agent the $A G_{T X / P L^{*}}\left(P L, P L^{*}\right)$ one (that sharply increased the volume of $T X$ penalties for exceeding the MPV of pollutions) actively joined to management operations. A cycle of production volume reduction and recapture, that allowed one to keep pollution level near the maximum permissible value $P L^{*}=3.5$ at the time interval from $50^{\text {th }}$ to $235^{\text {th }}$ computation step, arose in the management system. In parallel with this control loop, the mechanism for controlling $S$ balance of pollutant accumulation and assimilation rates operated as well. Due to low assimilation rate (high value of $S$ balance), $T X$ penalties and $E$ production cost remained high, and this fact did not allow resuming the previous production volume after the $235^{\text {th }}$ step of computations. This is evidenced by $S$ balance graph denoted by "1 $\%$ " inscription in the Fig. 4, $a$.
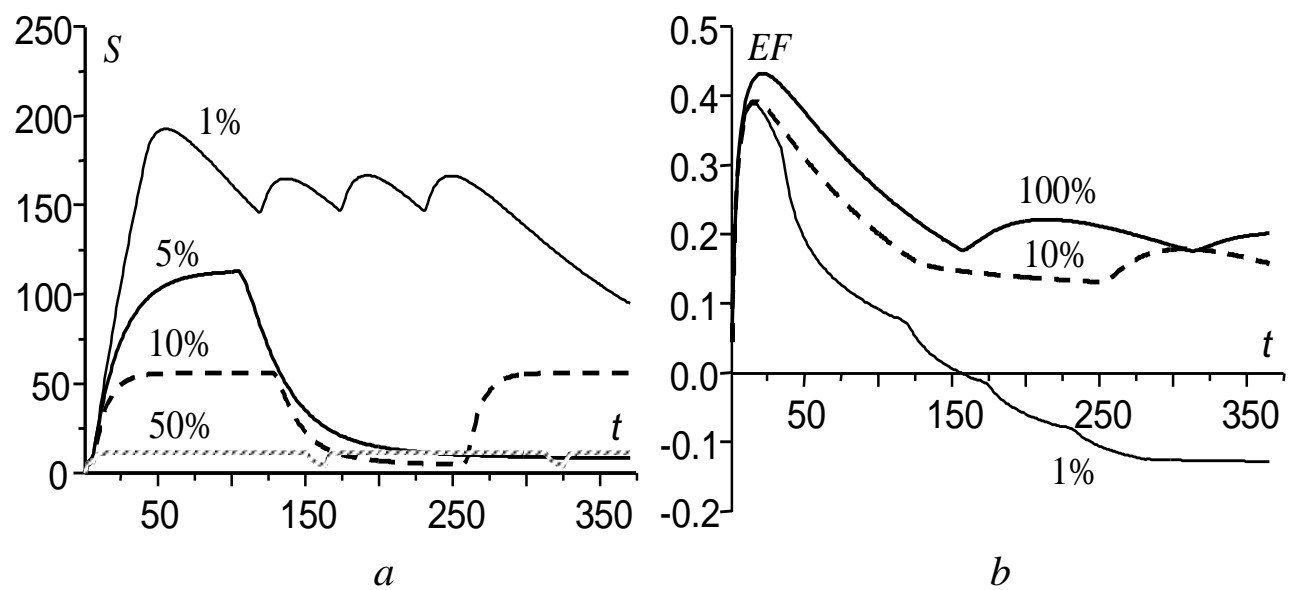

Fig. 4. $E F$ production profitability dependence on $S$ balance of pollution accumulation and assimilation rates in the sea with no regard to the effect of temperature dynamics of water masses. Assimilation rate of pollutant volume accumulated due to biochemical decomposition reactions is given in percent.

The dependence of $E F$ production profitability on $S$ balance of pollution accumulation and assimilation rates in the sea with no regard to the effect of temperature dynamics of water masses is represented in Fig. $4, b$. It follows from 
the given scenarios that profitability began to decrease sharply when assimilation rate of pollutions became lower than $10 \%$ of their volume per time unit. Thus, the effect of product release volume management (the graphs of these volumes are given in Fig. 3) manifests itself. The sharpest production profitability decline was observed at low assimilation rates, i.e. at high pollution concentrations.

In the next experiment calculations of ecological-economic processes were carried out taking into account the following external effects on the marine ecosystem: changes in the temperature $T W$ and the wind velocity modulus $W F$. To perform these experiments, the scenarios of intra-annual variability of external effects, represented in Fig. 5, $a$, were simulated. For comparing with the previous computations (in which $T W$ and $W F$ effects were not taken into account), biochemical decomposition rate of pollutants equal to $1 \%$ of their volume per unit time, which corresponded to the maximum value of assimilation rate function $R_{\max }=0,01$, was chosen.

The scenarios of ecological-economic processes obtained in this experiment are represented in Fig. 5, $b-f$. The graph of pollution assimilation rate function $R(t)$ calculated by the formulas $(13)-(15)$ is given in Fig. 5, c. Scenarios of production volumes $V$ and marine environment pollution concentration $P L$ (Fig. $5 b-d$ ) were constructed with regard to all factors affecting the assimilation of pollutions: biochemical decomposition rate with $R=0,01$, temperature $T W$ and wind velocity modulus $W F$. In the graphs for all variables of the model these conditions are denoted as " $1 \%+T W+W F$ ".

$R(t)$ function was calculated by the formula (13), taking into account dynamical factors of effect. Its intra-annual variability $R(t)$ graph is represented in Fig. 5, c. It is known that with the sea temperature increase, pollutant biochemical decomposition reaction rate also increases. Besides, under effect of near-water wind an intensive mixing of upper layer occurs. This promotes the dissipation of suspended phase and decomposition of the dissolved phase of pollutions [3]. This effect is clearly visible in Fig. 5, $b, d-f$. From a comparison of the obtained scenarios with the graphs of the processes shown in Fig. 3, b, $d$, it follows that dynamic factors greatly increased pollutant assimilation rate and thus significantly affected the management of ecological-economic processes. Pollution concentration scenario shown in Fig. 5, $d$ was kept at $P L$ level equal to 2.2, whereas in Fig. 3, $d$ it exceeded the MPV $\left(P L^{*}=3.5\right)$.

Penalties for pollution were associated mainly with the balance of pollution accumulation and assimilation rates, i.e. with $R(t)$ function value. Production volume reduction occurred at the $146^{\text {th }}$ step of the calculation when its production cost $E$ exceeded the cost of the generalized product $P^{*}$. However, the production was already resumed at the $167^{\text {th }}$ step, as $T X$ penalties were sharply reduced due to a decrease in the balance of accumulation and assimilation rates below the control value $S^{*}=5$ (Fig. $5, e$ ). A second product release limitation occurred at the $315^{\text {th }}$ step of computations when the balance of pollution accumulation and assimilation rates decreased below $S^{*}=5$ value again. The reason for it was a simulated seasonal sea temperature decrease (Fig. 5, a) Thus, the experiments revealed a 
significant effect of thermal and dynamic factors on the assimilation rate of pollutants: the obtained scenarios of ecological-economic processes were more like a $P L$ scenario in Fig. 3, $c$, when the assimilation rate was the maximal $\left(R_{\max }=1\right)$ due to biochemical processes.
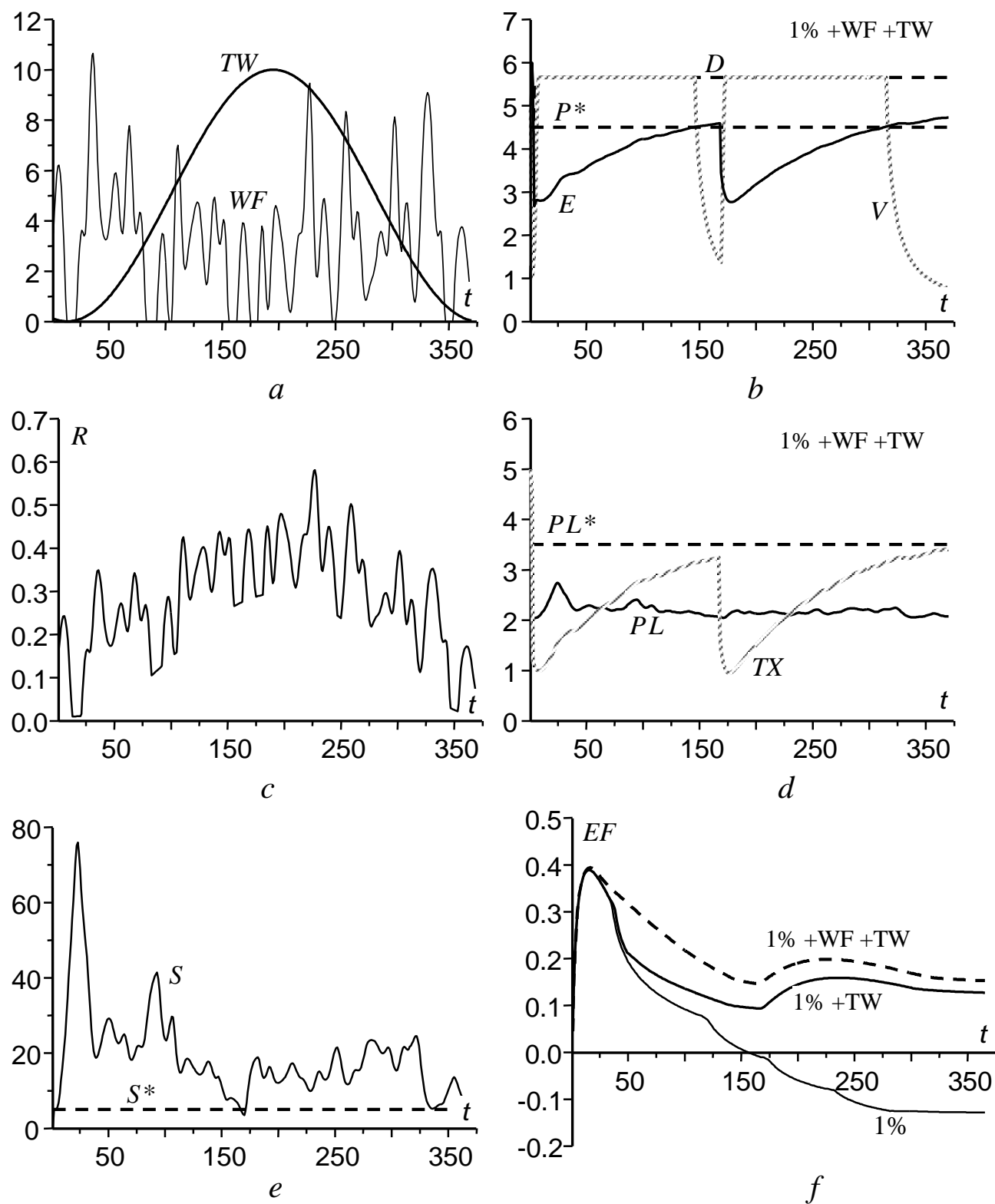

Fig. 5. The effect of sea temperature $T W$ and wind velocity modulus $W F$ on ecological-economic processes with the biochemical assimilation rate of pollutions $R_{\max }=0,01$ ( $1 \%$ of their volume per unit time): $a$ - simulated scenarios $T W$ and $W F ; b, d$ - model variables with regard to $T W$ and $W F$ $(1 \%+T W+W F) ; c-R(t)$ assimilation rate function; $e-$ the balance of volumes of accumulated and assimilated pollutions; $f$ - production profitability without taking into account $T W$ and $W F$ (1\%), with regard to $T W(1 \%+\mathrm{TW})$, with regard to $T W$ and $W F(1 \%+T W+W F)$ 
Conclusion. In the given paper a general method for managing a complex system that includes a coastal socio-production complex and an ecosystem of the coastal marine environment is considered. Coastal subsystem of the complex saved resources for utilization of industrial and domestic wastes at the expense of the assimilative resources of the sea, while the objectives of rational nature management consisted in preventing irreversible degradation of the marine ecosystem. The purpose of this study was to test the proposed mechanisms for management of ecological-economic processes the application of which is possible with the introduced assumptions. It was assumed that coastal ecosystem assimilative capacity was determined by the intensity of biochemical decomposition processes of harmful substances carried out into the sea with the coastal runoff. The intensity, in its turn, depended on the sea temperature and dynamic activity of water masses. For taking into account all the affecting factors, the assimilative process rate function, which determines the dynamic balance of pollution accumulation and assimilation [7 - 15] in comparison with the pollutant flux velocity, was introduced.

A scheme of cause-effect relationships between the marine environment pollution level and penalties that limit the flux of pollutants by the reduction of production profitability is proposed. The formalization of this scheme by the Adaptive Balance of Causes method allowed one to construct a simulation model for carrying out the computational experiments. According to their results, the following conclusions are drawn:

- adaptive simulation model (10) - (24) can be used for forecasting the scenarios of coastal subsystem production processes (the volume of generalized product manufacturing, production cost, profitability) in parallel with the scenarios of pollutant concentration and balance of accumulated and assimilated pollution volumes;

- due to the inclusion of management agents in the model, it became possible to determine the most advantageous modes of the marine environment assimilative capacity use by varying the amount of penalties for pollution;

- the model takes into account the fact that the sea temperature and wind mixing of water masses significantly increase the marine environment assimilative capacity.

Further development of the proposed approach to the complex "Coastal runoff - Coastal marine environment" system management involves specification of the source and chemical composition of pollutions getting into the sea, as well as detailing of the marine ecosystem model (its variables are the most sensible to such an effect).

Acknowledgements. The study was performed during the scheduled research of Federal State Budget Scientific Institution "Marine Hydrophysical Institute of RAS" on the project No. 007-00694-16 PR "Fundamental oceanography".

\section{REFERENCES}

1. Daly, H. and Farley, J., 2010. Ecological Economics: Principles and Applications. $2^{\text {nd }}$ edition. Washington: Island Press, $544 \mathrm{p}$. 
2. Voinov, A., 2008. Systems Science and Modeling for Ecological Economics. New York: Academic Press, 430 p.

3. Ofiara, D.D. and Seneca, J.J., 2001. Economic Losses from Marine Pollution: A Handbook for Assessment. Washington: Island Press, $320 \mathrm{p}$.

4. Timchenko, I.E., Igumnova, E.M. and Timchenko, I.I., 2000. Sistemnyy Menedzhment $i$ ABCTekhnologii Ustoychivogo Razvitiya [System Management and ABC-Technologies of Sustainable Development]. Sevastopol: Ecosi-Gidrofizika, 225 p. (in Russian).

5. Timchenko, I.E. and Igumnova, E.M., 2011. Control over the Ecological-Economic Processes in the Integral Model of the Coastal Zone of the Sea. Physical Oceanography, [e-journal] 21(1), pp. 45-62. doi:10.1007/s11110-011-9103-9

6. Timchenko, I.E., Igumnova, E.M. and Timchenko, I.I., 2016. Adaptive Balance Models for Environmental-Economic Systems. Create Space Independent Publishing Platform, 486 p. Available at: https://www.amazon.com/dp/1530208831 [Accessed 10 July 2016].

7. Samhouri, J.F. and Levin, P.S., 2012. Linking Land- and Sea-Based Activities to Risk in Coastal Ecosystems. Biological Conservation, [e-journal] 145(1), pp. 118-129. https://doi.org/10.1016/j.biocon.2011.10.021

8. Guerry, A.D., Ruckelshaus, M.H., Arkema, K.K., Bernhardt, J.R., Guannel, G., Kim, Ch.-K., Marsik, M., Papenfus, M. and Toft, J.E. [et al.], 2012. Modeling Benefits from Nature: Using Ecosystem Services to Inform Coastal and Marine Spatial Planning. International Journal of Biodiversity. Science, Ecosystem Services and Management, [e-journal] 8(1-2), pp. 107-121. http://dx.doi.org/10.1080/21513732.2011.647835

9. Halpern, B.S., Walbridge, S., Selkoe, K.A., Kappel, C.V., Micheli, F., D'Agrosa, C., Bruno, J.F., Casey, K.S. and Ebert, C. [et al.], 2008. A Global Map of Human Impact on Marine Ecosystems. Science, [e-journal] 319(5865), pp. 948-952. doi:10.1126/science.1149345

10. Heckbert, S., Baynes, T. and Reeson, A., 2010. Agent-Based Modeling in Ecological Economics. Annals of the New York Academy of Sciences, [e-journal] 1185, pp. 39-53. doi:10.1111/j.1749-6632.2009.05286.x

11. Crépin, A.-S., Norberg, J. and Mäler, K.-G., 2011. Coupled Economic-Ecological Systems with Slow and Fast Dynamics - Modelling and Analysis Method. Ecological Economics, [ejournal] 70(8), pp. 1448-1458. https://doi.org/10.1016/j.ecolecon.2011.02.004

12. Goetza, R.U. and Zilbermanb, D., 2000. The Dynamics of Spatial Pollution: The Case of Phosphorus Runoff from Agricultural Land. J. Econ. Dyn. Control, [e-journal] 24(1), pp. 143163. https://doi.org/10.1016/S0165-1889(98)00067-0

13. Christie, P., 2005. Is Integrated Coastal Management Sustainable? Ocean Coast. Manag., [ejournal] 48(3-6), pp. 208-232. https://doi.org/10.1016/j.ocecoaman.2005.04.002

14. Elofsson, K., Folmer, H. and Gren, I.-M., 2003. Management of Eutrophicated Coastal Ecosystems: A Synopsis of the Literature with Emphasis on Theory and Methodology. Ecological Economics, [e-journal] 47(1), pp. 1-11. doi:10.1016/j.ecolecon.2003.09.001

15. Shogren, J.F., Parkhurst, G.M. and Settle, C., 2003. Integrating Economics and Ecology to Protect Nature on Private Lands: Models, Methods, and Mindsets. Environ. Sci. Policy, [ejournal] 6(3), pp. 233-242. https://doi.org/10.1016/S1462-9011(03)00041-8 